\title{
Contamination of Frozen Broiler Chicken Meats with Antimicrobial Resistant Thermophilic Campylobacter in Morogoro, Tanzania
}

\author{
Msetule $\mathrm{L}^{1}$, Komba $\mathrm{EVG}^{2 *}$, Kimera $\mathrm{SI}^{3}$ and Mdegela $\mathrm{RH}^{3}$ \\ ${ }^{1}$ Master Students, Sokoine University of Agriculture, Tanzania \\ ${ }^{2}$ Senior Lecturer, Sokoine University of Agriculture, Tanzania \\ ${ }^{3}$ Professor, Sokoine University of Agriculture, Tanzania
}

Received: September 12, 2017; Published: October 03,2017

*Corresponding author: Komba EVG, Department of Veterinary Medicine and Public Health, College of Veterinary Medicine and Biomedical Sciences, Sokoine University of Agriculture, Tanzania, Tel:+255713 584054; Email: babagrid@yahoo.com

\begin{abstract}
Purpose: Majority of the human bacterial gastroenteritis cases in both developed and developing countries in the world are caused by thermo tolerant Campylobacter spp, with C. jejuni and C. coli being more involved. These bacteria live in poultry and other animal's intestinal tracts without causing disease symptoms. Improper handling of carcasses during slaughter and evisceration increases the chance of contaminating the outer skin. Poor meat handling in the kitchen and poor storage during refrigeration causes cross contamination.

Methods: This cross-sectional study examined the occurrence of antimicrobial resistant thermophilic Campylobacter in frozen chicken meats in Morogoro Municipality. A total of 272 frozen broiler chicken carcasses were obtained from supermarkets ( $\mathrm{n}=90)$, meat shops ( $\mathrm{n}=90)$ and restaurants $(\mathrm{n}=92)$. Each carcass was divided into three parts i.e. breast, thighs and wing+neck, rinsed in peptone water. The rinses were then enriched in $5 \mathrm{ml}$ of Bolton broth in microerophilic atmosphere at $42^{\circ} \mathrm{C}$ for $24 \mathrm{hrs}$. Then the broth was streaked on Modified Charcoal Cefoperazone Deoxycholate Agar (mCCDA) plates followed by incubation at $42^{\circ} \mathrm{C}$ for $48 \mathrm{hrs}$. Presumptive colonies of Campylobacter spp. were sub cultured onto Mueller Hinton Agar and incubated at $42^{\circ} \mathrm{C}$ for $48 \mathrm{hrs}$ to obtain pure colonies. Pure Campylobacter colonies were then subjected to preliminary identification using biochemical tests and further confirmed by polymerase chain reaction (PCR). Antimicrobial Susceptibility testing was performed on C. Jejuni isolates by disc diffusion method on Mueller-Hinton agar supplemented with $5 \%$ of horse blood. The isolates were tested for resistance against ten antimicrobials namely tetracycline, gentamycin, ciprofloxacin, azithromycin, erythromycin, norfloxacin, chloramphenical, amoxicilin, nalidixic acid and cephalocin.
\end{abstract}

Results: Occurrence of thermophilic Campylobacter spp. in the sampled birds was at a tune of $61.0 \%$. Based on sampling locations the levels of contaminated chicken carcasses were $82.6 \%, 62.0 \%$ and $37.8 \%$ for restaurants, shops and supermarkets, respectively. Majority of isolates (72.4\%) were Campylobacter jejuni and the remaining proportion (27.6\%) was accounted for by C. coli. Frequencies of contamination were comparable between wing+neck and thighs. Wing+neck and thighs had significantly higher frequencies of contamination than breasts $(\mathrm{P}<0.05)$. Antibiotic resistance test results for $\mathrm{C}$. jejuni indicated that higher levels $(>80 \%)$ of resistance were observed for cephalothin, chloramphenical, nalidixic acid, amoxicillin and tetracycline. Lower levels of resistance $(<15 \%)$ were observed for erythromycin, norfloxacin, azithromycin, ciprofloxacin and gentamicin.

Conclusion: This study confirms that in our setting a high frequency of commercial broiler chickens are positive for antimicrobial resistant Campylobacter at the time of slaughter. This phenomenon derives in high contamination of carcasses during the slaughter process thereby constituting a substantial public health hazard. Freezing of carcasses does not completely remove this bacterium as seen from this study. Control strategies for these pathogens at flock level are recommended to avoid contamination of the final product. Animal products should be properly handled and thoroughly cooked in order to make sure that safe products are consumed.

Keywords: Broiler meat; C Coli; C Jejuni; Restaurants; Supermarkets; Tanzania

Abbreviations: Mccda: Modified Charcoal Cefoperazone Deoxycholate Agar; PCR: Polymerase Chain Reaction

\section{Introduction}

Thermo tolerant Campylobacter spp. in particular C. jejuni and C. Coli, are among the leading causes of human bacterial gastroenteritis

in the world [1-4]. Of the two species, C. Jejuni is responsible for majority (80-90\%) of the food-borne Campylobacter infections 
[5]. The organisms primarily colonize the small intestines of a wide variety of animals, avian being the most common reservoirs $[6,7]$. The frequently mentioned risk factor for human infections is consumption of raw or undercooked poultry meat [8,9]. Other food products can serve as sources of human infection through crosscontamination [10].

A large number of Campylobacter spp. is harbored by the intestinal tract of chicken, especially the ceca and colon. During processing activities, especially during evisceration where the tract may leak or rupture, its contents can easily contaminate chicken carcasses, surface water and environments [11,12]. During slaughter, contamination of chicken carcasses can also occur indirectly through contaminated equipment and water. As a survival mechanism, campylobacter's become trapped in folds and crevices of the skin particularly in the feather follicles [13]. As a result several studies, most of them conducted in developed countries, have shown that there is a high prevalence of Campylobacter in raw poultry meat and more than one species can be present in a sample $[14,15]$.

Studies elsewhere have demonstrated that Campylobacter survive in raw and cooked poultry meat during refrigerated or frozen storage [12,16-18]. The studies report frequent isolation of C. jejuni and C. coli in retail chicken carcasses [14], with the former occurring more. The aim of this study was therefore to establish the contamination levels of frozen broiler meat with thermophilic Campylobacter organisms and determine antimicrobial resistance profiles of the associated isolates in Tanzania. Results of the study complement findings in most of case control studies that report consumption of poultry meat to be among the potential risk factors for human Campylobacter infections.

\section{Materials and Methods \\ Study Area}

The study was conducted in Morogoro Municipality, western Tanzania. Geographically the Municipality is located between longitude 35o15' to 38030' East and latitude 5o15' to 1000 ' South on slopes of Uluguru Mountains at an altitude of $526.0 \mathrm{~m}$ above sea level. It has a bimodal rainfall pattern with 188.5-409.4 mm and temperature ranges from 15.0 to $33.10 \mathrm{C}$. The Municipal is featured by backyard exotic chicken production involving both broilers and layers. At slaughter age broilers are either bought on retail basis by consumers at farm gate or whole sale basis by supermarket, butchers and restaurant owners; with the birds being slaughtered at the farm.

\section{Study design, Sample Size Determination and Sampling Procedure}

A cross sectional study design was adopted. The study involved collection of frozen chicken samples from meat shops, supermarkets and restaurants. The sample size was estimated by using the formula $\mathrm{N}=\mathrm{Z}^{2} \mathrm{P}(1-\mathrm{P}) / \mathrm{d}^{2}$ Martin et al. [19]. Where by $\mathrm{N}=$ is the sample size, $\mathrm{Z}=$ is a multiplier from the normal distribution i.e. $1.96, \mathrm{P}=$ is expected/known prevalence and $\mathrm{d}^{2}=$ is degree of accuracy desired (0.05) with a $95 \%$ confidence interval. Based on a previous study done in a nearby country of Kenya [20], a known prevalence of $77 \%$ was used. Using the above formula a sample size of 272 chicken carcasses was obtained. Simple random sampling was adopted. During sampling dressed chicken carcasses were handled in individual clean plastic bags. Following collection the samples were immediately conveyed to the laboratory on ice.

\section{Laboratory Procedures}

\section{Sample Processing and Enrichment Procedures}

The detection of thermo tolerant Campylobacter in foods requires selective enrichment broths at $42^{\circ} \mathrm{C}$ under microaerophilic atmosphere [21] thus providing adequate conditions for growth of thermo tolerant species, protection against toxic oxygen derivatives and recovery of injured cells [22]. In the laboratory each frozen chicken carcass was cut into three portions i.e. wings+neck, thighs and breasts. The portions were then rinsed with $200 \mathrm{~mL}$ bufferedpeptone water (Oxoid Ltd, Basingstoke, U.K.) and then gently shaken for $1 \mathrm{~min}$. For the test, $25 \mathrm{~mL}$ from the $200 \mathrm{~mL}$ rinsate and $25 \mathrm{~mL}$ of 2 $\times$ Bolton broths (Oxoid Ltd, Basingstoke, U.K.) were mixed and then incubated at $42^{\circ} \mathrm{C}$ for $24 \mathrm{~h}$ under Micro-aerobic condition.

\section{Isolation of Campylobacter Spp.}

Following shaking, a loopful of enrichment was streaked on mCCDA agar plates (Oxoid Ltd, Basingstoke, U.K.) for primary isolation of thermophilic Campylobacter. The agar plates were incubated at $42^{\circ} \mathrm{C}$ under microaerobic condition for $48 \mathrm{hrs}$. Presumptive Campylobacter colonies were subculture onto Mueller- Hinton agar supplemented with preston Campylobacter selective supplement (Oxoid Ltd, Basingstoke, U.K.) and then incubated at $42^{\circ} \mathrm{C}$ for $48 \mathrm{hrs}$ under microearobic condition.

\section{Identification of Thermophilic Campylobacter Isolates Preliminary Identification}

Presumptive identification of thermophlic Campylobacter spp. was done by traditional morphological methods like colonial characteristics and microscopy (Motility and Gram Staining); and Biochemical Methods (oxidase and catalase reactions, hippurate hydrolysis, and susceptibility to Cephalothin and Nalidixic acid $[23,24]$.

\section{Confirmation of Campylobacter spp.}

Polymerase chain reaction was used for definitive identification of the Campylobacter spp. C. jejuni and C. coli were identified using species specific PCR adopting a method described earlier by Nachamkin et al. [25]. Genomic DNA to be used for PCR was extracted from bacterial suspensions by boiling at $100^{\circ} \mathrm{C}$ for $10 \mathrm{~min}$. Primers F,5'CTATTTTATTTTTGAGTGCTTGTG3' and R,5'GCTTTATTTGCCATTTGTTTTATTA3' (TAG COPENHAGEN A/S, Denmark) were used to amplify the mapA gene of C. jejuni, where as primers F,5'ATTTGAAAATTGCTCCAACTATG3' and R,5'TGATTTTATTATTTGTAGCAGCG3' (Tag Copenhagen A/S, Denmark) were used to amplify the ceuE gene of C. Coli. Each reaction was performed in a $50 \mu \mathrm{l}$ total volume containing $10 \mu \mathrm{l}$ primer mix (12pmol of each primer), $25 \mu$ l Green master mix, $2 \mu \mathrm{l}$ DNA template and $13 \mu \mathrm{l}$ of nuclear free water. Amplification 
reactions were done by using an automated thermal cycler machine (Crocodile II Appligene Inc. Pleasanton CA, USA). The amplification process started with denaturation at $94 \mathrm{oC}$ for five minutes, then 35 cycles at $920 \mathrm{C}$ for 30 seconds followed by annealing at $550 \mathrm{C}$ for one and half minutes and extension at $72 \mathrm{oC}$ for two and half minutes, then incubated at $720 \mathrm{C}$ for 5 minutes and maintained at $4 \mathrm{oC}$ until analysed. The amplification generated 589bp and 462bp DNA fragments corresponding to Campylobacter jejuni and Campylobacter coli respectively. The PCR products were analyzed on a $0.8 \%$ agarose gel stained with $0.3 \mathrm{~g} / \mathrm{ml}$ ethidium bromide and were visualized under UV light. A $100 \mathrm{bp}$ ladder was used as a molecular size standard.

\section{Antimicrobial Resistance Testing of Thermophilic Campylobacter Isolates}

Campylobacter isolates were tested for resistance to different antimicrobials by the disc diffusion method on Muller Hinton Agar (Oxoid Ltd, Basingstoke, UK) supplemented with 5\% of horse blood. Briefly, bacterial suspensions were prepared in a sterile normal saline and adjusted to a turbidity equivalent to 0.5 McFarland standards. The suspensions were inoculated onto Mueller-Hinton agar plates and dried; and then antibiotic discs distributed over the inoculated plates using a BBL Sensi-disc dispenser (Oxoid Ltd, Basingstoke, UK). The plates were then incubated at $42^{\circ} \mathrm{C}$ for 48 hours under microaerobic conditions. After 48 hours diameters of inhibition zones were measured and results interpreted in accordance with interpretive criteria provided by NCCLS [26] and manufacturer's instructions. Sixty Campylobacter isolates were tested for resistance against the following antimicrobials;

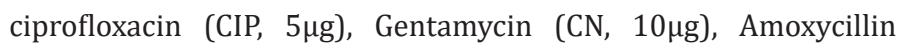

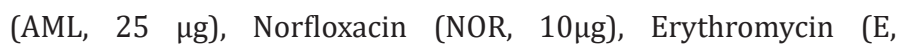

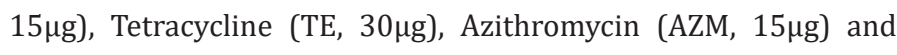

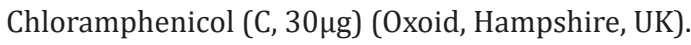

\section{Data analysis}

Collected data in this study were first entered and cleaned in Microsoft Office Excel® 2007 (Microsoft Corporation, One Microsoft Way, Redmond, 98052-7329, USA) and imported into EpiInfo version 7 (CDC Atlanta, USA) for analysis. Contamination levels of different parts of the carcasses were determined by computing descriptive statistics. Differences in the contamination levels were determined by computing the chi square. A p value of 0.05 or less was considered statistically significant.

\section{Results}

\section{Occurrence of Thermophillic Campylobacter and Species Distribution}

A total of 272 frozen chicken carcasses were collected from different sources in the following order, shops ( $n=90)$, supermarkets $(n=90)$ and restaurants $(n=92)$. Storage of the carcasses differed from one source to another. In shops and restaurants all carcasses were pooled together in freezers at $-20^{\circ} \mathrm{C}$; whereas in supermarkets each carcass was packaged in a clean plastic bag and stored in freezer at $-20^{\circ} \mathrm{C}$. Overall $61.0 \%(\mathrm{n}=166 / 272)$ of frozen chicken meat samples were found to be contaminated with Campylobacter spp. as noted by growth of characteristic colonies on mCCDA and on $\mathrm{MH}$ agar. According to the sources of the samples the frequencies of chicken carcass contamination were $62 \%$ for shops, $37.8 \%$ for supermarkets and $82.6 \%$ for restaurants. The differences in these frequencies of Campylobacter detection were statistically significant at a $\mathrm{p}$-value $\leq 0.05$.

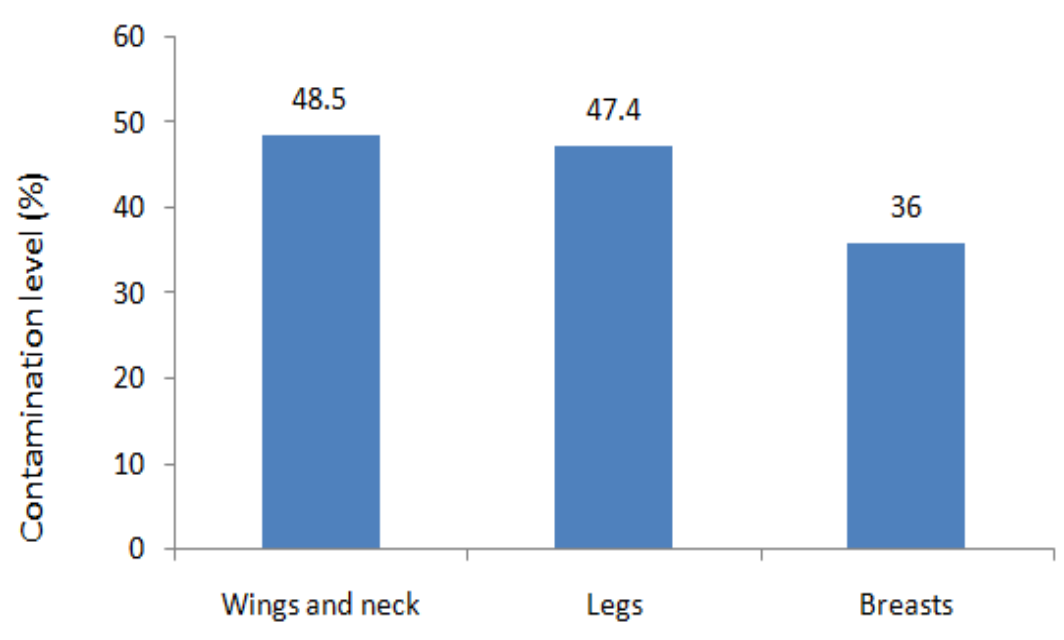

Chicken carcass portion

Figure 1: Frequencies of contamination of Different Portions of Broiler Thermophilic Carcasses with Campylobacter.

\section{Distribution of thermophillic Campylobacter in Different Carcass Portions}

Contamination, of different chicken carcass portions, with thermophillic Campylobacter spp. ranged from $36.0 \%$ to $48.5 \%$ (Figure 1). Contamination levels were similar for wings and thigh. The contamination levels of these portions were however significantly higher $(\mathrm{p} \leq 0.05)$ when compared to that of breasts.

\section{Antimicrobial Resistance Profiles}

A total of 60 Campylobacter Jejuni isolates were tested for resistance against ten antimicrobial agents. The levels of resistance 
among the isolates ranged from $3.3 \%$ to $100.0 \%$ (Table 1). The highest resistance levels were observed for amoxicillin and

Table 1: Antimicrobial resistance profiles of 60 Campylobacter Jejuni isolated from frozen chicken carcasses in Morogoro, Tanzania.

\begin{tabular}{|c|c|c|}
\hline \multirow{2}{*}{ Antimicrobial Agent Tested } & \multicolumn{2}{|c|}{ Resistant of Isolates } \\
\cline { 2 - 3 } & Number & Proportion (\%) \\
\hline Ciprofloxacin & 3 & 5.0 \\
\hline Erythromycin & 8 & 13.3 \\
\hline Chloramphenical & 57 & 95.0 \\
\hline Norfloxacin & 4 & 6.7 \\
\hline Amoxicillin & 60 & 100.0 \\
\hline Cephalothin & 49 & 81.7 \\
\hline Nalidixic acid & 59 & 98.3 \\
\hline Gentamicin & 2 & 3.3 \\
\hline Tetracycline & 60 & 100.0 \\
\hline Azithromycin & 4 & 6.7 \\
\hline
\end{tabular}

\section{Discussion}

The current study reveals occurrence of thermophilic Campylobacter spp. in frozen broiler meat. There are several other reports describing Campylobacter spp. contamination in frozen retail poultry meats and/or by-products in the world in spite of their sanitary conditions [15]. Such reports, from both developed and developing countries, reveal that poultry meat is the food vehicle most frequently contaminated with Campylobacter spp. [27]. These findings, along with the findings in this study are suggestive of high prevalence of Campylobacter at flocks level as previously reported by Stern et al. [28] and Arsenault et al. [29] who observed a positive correlation between the contamination of carcasses and the high positivity rates for Campylobacter of flocks at the farm level. The ability of Campylobacter spp. to survive refrigeration and freezing has a huge implication to food safety and public health given that ingestion of only 500C. Jejuni cells has resulted into illness in human experimental infections [30,31].

The prevalence of Campylobacter contamination on poultry products worldwide is reported to be in the range of 0 to $100 \%[15,32,33]$. The obtained prevalence of frozen chicken contamination in this study (61.0\%) falls within this stated range. More or less similar contamination prevalence's have been reported in Brazil 62.2\% [34] and in Iran 63.0\%; [27]. Low prevalence's of retail poultry contamination with Campylobacter spp. have been reported in Brazil 47.5\%; [35], Japan 45.8\%; [36], Chile 45\% [37], USA 41.0\% [38] and in Bulgaria 35.2\% [39]. Some years back Lee et al. [40] showed that $\mathrm{C}$. Jejuni was able to survive for up to almost two months under frozen storage at $-20^{\circ} \mathrm{C}$, which is the temperature found in most domestic freezers. A more or less similar observation was made by Georgsson who demonstrated survival of Campylobacter spp. in chicken meat stored at $-20^{\circ} \mathrm{C}$ for 31 days. As several studies demonstrated that Campylobacter survive in raw and cooked poultry meat during refrigerated or frozen storage $[12,16,17,18,40]$, frozen storage of foods cannot be considered a safety assuring procedure. Studies however report that frozen poultry meats and by-products have shown tetracycline, whereas the lowest resistance level was recorded for Gentamycin.

lower prevalence compared with poultry meats and by-products. This can be attributed to the fact that frozen conditions damage Campylobacter spp. cells and decrease their viability $[17,41]$.

In the present study samples were collected from meat shops, restaurants and supermarkets. In meat shops and restaurants carcasses were found to be stored in freezers pooled together providing a room for cross contamination. This was reflected in the prevalence of positive chicken carcass samples detected from the different sources, being significantly higher for those from shops and restaurants. This further explains possibilities for cross contamination of food products either during storage or preparation in the kitchen once hygienic practices are not observed.

We noted in this study that C. Jejuni was the predominant thermophilic Campylobacter species responsible for causing contamination of poultry meat. This observation is similar to what has been observed in other studies elsewhere in which authors reported C. Jejuni to be the most prevalent thermophilic Campylobacter spp. in chickens than others [42-46]. Some other studies have however reported findings contrary to the current observation. These include a study in Thailand in which the authors found that $\mathrm{C}$. coli were more frequently isolated from retail poultry meats and by-products compared to $\mathrm{C}$. jejuni. Two different studies in the same country found that $\mathrm{C}$. coli and C. jejuni were almost comparably prevalent in poultry at farms, with the ratio of C. coli to C. jejuni however drastically increasing via processing plants to markets $[47,48]$. The authors suggested the possibility of transmission of Campylobacter spp. from non-poultry sources to poultry, especially at markets. Fernández and Pisón [49] who also found a higher prevalence of C. coli as compared to C. jejuni in chicken liver samples suggested that $\mathrm{C}$. coli could be more resistant to injury resulting from exposure to low temperatures and adverse ambient conditions.

During collection of swab samples chicken carcasses were portioned into wings and necks, breasts and thighs. Culture results indicated that wings and necks; and thighs had higher levels of contamination with Campylobacter spp. than breast samples. This observation could be linked to the fact that during the chicken slaughter process, particularly during the process of evisceration, most people prefer to hold wings, neck and thighs. For that matter, once unfortunately there is rupture of intestines followed by fecal contamination to people hands these areas preferred for handling easily get contaminated. A similar finding to what was observed in this study was reported in Bulgaria in which $35.2 \%$ of frozen poultry carcasses were contaminated by Campylobacter spp. with high percentages of $91.1 \%$ and $88.9 \%$ detected in the wing and thigh cuts, respectively [39]. Further, our results are supported by a study done in California USA in which the authors found a higher contamination with Campylobacter jejuni of chicken wings purchased from retail outlets on the day of arrival at the supermarket [50]. Other authors cautioned that high Campylobacter load in chicken wings could increase the probability of pathogen transfer to other surfaces through cross contamination and inappropriate 
handling during meal preparation and cooking [51]. It has been suggested earlier that higher Campylobacter contamination levels in chicken wings might be attributed to imperfect scalding, postscalding contamination, or due to the combination of both [52].

Worldwide reports indicate that antimicrobial resistance is increasing in food, food animals and human bacterial isolates; including Campylobacter [53-57]. Campylobacter isolates recovered from frozen broiler meat in the present study demonstrated varying proportions of resistance to different antimicrobials; ranging from $3.3 \%$ to $100.0 \%$. Higher levels of resistance were noted for Amoxicillin (100.0\%), Tetracycline (100.0\%), Nalidixic acid (98.3\%), Chloramphenical (95.0\%) and Cephalocin (81.7\%) whereas the lowest resistance level $(3.3 \%)$ was recorded for gentamycin. Similar, lower and higher frequencies of resistance to these different antimicrobial agents have been reported in other studies [14,46,58-64].

Some C. Jejuni isolates in this study were resistant to ciprofloxacin and erythromycin, the known to be drugs of choice for treatment of cases of human campylobacteriosis that require therapeutic intervention i.e. persistent or complicated cases and those involving immuno-compromised individuals [65] Resistance to these two antimicrobial agents was low in this study indicating that they may still be useful in the treatment of human campylobacteriosis in the country. A similar observation of low resistance to ciprofloxacin among thermophilic Campylobacter isolates was reported in a recent studies conducted in the country $[9,66]$. The authors however found higher frequencies of resistant isolates to erythromycin which is contrary to what we report in this study. Studies in Nigeria $[67,68]$ reported that ciprofloxacin was effective against all the strains of Campylobacter tested. Many other studies have revealed variability in proportions of resistant Campylobacter isolates to ciprofloxacin and erythromycin [57,6973]. Beatty et al. [74] reported that the resistance of Campylobacter to erythromycin is increasing and varies between $12 \%$ and $95 \%$.

All the C. jejuni isolates obtained in this study were resistant to amoxicillin and tetracycline. A higher level of resistance to tetracycline among C. Jejuni isolates was reported previously in the country [75]. Recent studies in the country have however reported a moderate frequency of tetracycline resistance among thermophilic Campylobacter isolates $[9,66]$. In these studies however the authors reported higher resistance levels to nalidixic acid among Campylobacter isolates which is in line with this study. Tetracyclines are the most extensively used drugs in veterinary medicine in Tanzania. In Canada, Gaudreau and Gilbert [57] reported that the rate of resistance of $\mathrm{C}$. Jejuni to tetracycline rose from $19.1 \%$ to $55.7 \%$ in a period of 10 years. Tetracyclines are known to be relatively cheap and have a broad spectrum of activity. For this reason, they have been broadly used in the prophylaxis and therapy of human and animal infections and to promote animal growth.

\section{Conclusion}

The current study reveals contamination of frozen broiler meat with antimicrobial resistant thermopilic Campylobacter.

\section{Recommendations}

We recommend control plans for the pathogens at all levels from farm to table so as to stem human infections attributable to broilers as sources. Further research is needed to investigate the physiological mechanisms underlying the ability of C. Jejuni to survive following prolonged exposure to low temperatures in spite of being very fragile and fastidious. Variations in resistance observed over time underscore the need for continued public health monitoring of Campylobacter resistance from humans, animals, and food [76].

\section{References}

1. Blaser MJ (1995) Campylobacter jejuni and related species. Microbiology (ASM) Press, Washington DC, USA, pp. 1948-1956.

2. Lastovica AJ, Skirrow M (2000) Clinical significance of Campylobacter and related species other than Campylobacter jejuni and C. coli. ASM Press, Washington DC, USA, pp. 89-120.

3. Aarestrup FM, Engberg J (2001) Antimicrobial resistance of thermophilic Campylobacter. Veterinary Research 32(3-4): 311-321.

4. Rivoal K, Ragimbeau C, Salvat G, Colin P, Ermel G (2005) Genomic diversity of Campylobacter coli and Campylobacter jejuni isolates recovered from free-range broiler farmsand comparison with isolates of various origins. Applied and Environmental Microbiology 71(10): 62166227.

5. Park SF (2002) The physiology of Campylobacter species and its relevance to their role as foodborne pathogens. International Journal of Food Microbiology 74(3): 177-188.

6. Newell DG, Fearnley C (2003) Sources of Campylobacter colonization in broiler chickens. Applied and Environmental Microbiology 69(8): 4343.

7. Adhikari B (2003) Sparrows, Flies and Rodents as Reservoirs of Campylobacter spp. on a Dairy Farm. MVSc thesis, Massey University, Palmerston North, New Zealand.

8. Cox NA, Richardson LJ, Buhr RJ, Fedorka Cray PJ, Bailey JS, et al. (2006) Natural Presence of Campylobacter spp. in Various Internal Organs of Commercial Broiler Breeder Hens. Avian Diseases 50(3): 450-453.

9. Komba EVG, Mdegela RH, Msoffe PLM, Nielsen LN, Ingmer H (2015) Prevalence, Antimicrobial Resistance and Risk Factors for Thermophilic Campylobacter Infections in Symptomatic and Asymptomatic Humans in Tanzania. Zoonoses and Public Health 62(7): 557-568.

10. Evans MR, Lane W, Frost JA, Nylen G (1998) A Campylobacter outbreak associated with stir-fried food. Epidemiology and Infection 121(2): 275279.

11. Scherer K, Bartelt E, Sommerfeld C, Hildebrandt G (2006) Quantification of Campylobacter on the surface and in the muscle of chicken legs at retail. Journal of Food Protection 69(4): 757-761.

12. Rosenquist H, Sommer HM, Nielsen NL, Christensen BC (2006) The effect of slaughter operations on the contamination of chicken carcasses with thermotolerant Campylobacter. International Journal of Food Microbiology 108(2): 226-232.

13. Corry JEL, Atabay HI (2001) Poultry as a source of Campylobacter and related organisms. Journal of Applied Microbiology 90: 96S-114S.

14. Kramer JM, Frost JA, Bolton FJ, Wareing DRA (2000) Campylobacter contamination of raw meat and poultry at retail sale: identification of multiple types and comparison with isolates from human infection. Journal of Food Protection 63(12): 1654-1659.

15. Suzuki H, Yamamoto S (2009) Campylobacter contamination in retail poultry meats and by products in the World: a literature study. Journal of Veterinary Medical Science 71: 255-261. 
16. Beuchat LR (1987) Efficacy of some methods and media for detecting and enumerating Campylobacter jejuni in frozen chicken meat. Journal Applied Bacteriology 62(3): 217-221.

17. Bhaduri S, Cottrell B (2004) Survival of cold-stressed Campylobacter jejuni on ground chickens and chicken skin during frozen storage. Applied and Environmental Microbiology 70(12): 7103-7109.

18. Paulsen P, Kanzler P, Hilbert F, Mayrhofer S, Baumgartner S, et al. (2005) Comparison of three methods for detecting Campylobacter spp. in chilled or frozen meat. International Journal of Food Microbiology 103(2): 229-233.

19. Martin SW, Meek AH, Willeberg P (1987) Veterinary epidemiology, Iowa State University Press / AMES, pp. 343.

20. Osano 0, Arimi S (1999) Retail poultry and beef as source of Campylobacter jejuni. East African Medical Journal 76(3): 141-143.

21. Bolton FJ, Robertson L (1982) A selective medium for isolating Campylobacter jejuni / coli. Journal of Clinical Pathology 35(4): 462467.

22. Donnison A (2003) Isolation of Thermotolerant Campylobacter Review and methods for New Zealand laboratories. Ministry of Health of New Zeeland.

23. Quinn PJ, Carter ME, Markey BK, Carter GR (1994) Clinical Veterinary Microbiology, Mosby-Year Book Europe Limited, London.

24. Donnison A (2003b) Procedures for Sampling, Handling \& Storage of Campylobacter Isolates. Ministry of Health, New Zealand.

25. Nachamkin I, Bohachick K, Patton CM (1993) Flagellin gene typing of Campylobacter jejuni by restriction fragment length polymorphism analysis. Journal Clinical Microbiology 31(6): 1531-1536.

26. NCCLS (2003) Performance standards for antimicrobial disk susceptibility tests. Approved standard. 8th ed. NCCLS document M2A8. National Committee for Clinical Laboratory Standards, Wayne, PA.

27. Taremi M, Mehdi Soltan Dallal M, Gachkar L, Moez Ardalan S, Zolfagharian K, et al. (2006) Prevalence and antimicrobial resistance of Campylobacter isolated from retail raw chicken and beef meat, Tehran, Iran. International Journal Food Microbiology108(3): 401-403.

28. Stern NJ, Fedorka Cray P, Bailey JS, Cox NA, Craven SE, et al. (2001) Distribution of Campylobacter spp. in selected U.S. poultry production and processing operations. Journal of Food Protection 64(11): 17051710 .

29. Arsenault J, Letellier A, Quessy S, Boulianne M (2007) Prevalence and risk factors for Salmonella and Campylobacter spp. carcass contamination in broiler chickens slaughtered in Quebec, Canada. Journal of Food Protection 70: 1820-1828.

30. Skirrow MB, Blaser MJ (2000) Clinical aspects of Campylobacter infection. Campylobacter, 2nd ed. ASM Press, Washington, DC, USA, p. 69-88.

31. Chan K, Tran HL, Kanenaka RY, Kathariou S (2001) Survival of Clinical and Poultry-Derived Isolates of Campylobacter jejuni at a Low Temperature $\left(4^{\circ} \mathrm{C}\right)$. Applied and environmental microbiology 67(9): 4186-4191.

32. Bryan FL, Doyle MP (1995) Health risks and consequences of Salmonella and Campylobacter jejuni in raw poultry. Journal of Food Protection 58(3): 326-344.

33. Jfrgensen F, Bailey R, Williams S, Henderson P, Wareing DRA, et al. (2002) Prevalence and numbers of Salmonella and Campylobacter spp. on raw, whole chickens in relation to sampling methods. International Journal Food Microbiology 76(1-2): 151-164.

34. Leitão MFF, Taniwaki MH, Uboldi Eiroa MN (1986) Campylobacter jejuni e C. coli no trato intestinal e superfície de carcaças de frango recém abatidos. Colet ITAL Campinas 16: 37-47.

35. Almeida PF, Serrano AM (1987) Ocorrência de Campylobacter fetus subspécie jejuni em carcaças de frango e suínos. Revista de Microbiologia 18(3): 279-283.
36. Ono K, Yamamoto K (1999) Contamination of meat with Campylobacter jejuni in Saitama, Japan. International Journal of Food Microbiology 47(3): 211-219.

37. Figueroa A, Adriazola P, Figueroa G, Ruiz M (2004) Campylobacter jejuni prevalence in poultry meats. Acta Microbiological 10: 133.

38. Williams A, Oyarzabal OA (2012) Prevalence of Campylobacter spp. in skinless, boneless retail broiler meat from 2005 through 2011 in Alabama, USA. BMC Microbiol 12: 184.

39. Stoyanchev T, Vashin I, Ring C, Atanassova V (2007) Prevalence of Campylobacter spp. in poultry and poultry products for sale on the Bulgarian retail market. Antonie van Leeuwenhoek 92(3): 285-288.

40. Lee A, Smith SC, Coloe PJ (1998) Survival and growth of Campylobacter jejuni after artificial inoculation onto chicken skin as function of temperature and packing conditions. Journal of Food Protection 61(12): 1609-1614.

41. Oyarzabal OA, Backert S, Nagaraj M, Miller RS, Hussain SK, et al. (2007) Efficacy of supplemented buffered peptone water for the isolation of Campylobacter jejuni and C. coli from broiler retail products. Journal of Microbiological Methods 69(1): 129-136.

42. Saleha AA, Mead GC, Ibrahim AL (1998) Campylobacter jejuni in poultry production and processing in relation to public health. World Poultry Science Journal 54(1): 50-57.

43. Wedderkopp A, Gradel KO, Jorgensen JC, Madsen M (2000) Pre-harvest surveillance of Campylobacter and Salmonella in Danish broiler flocks: a 2- year study. International Journal of Food Microbiology 68(1-2): 5359.

44. Harvey AS, Peter JW, Elli L, Cecilia TG, Sonia LR, et al. (2003) Domestic poultry raising practices in Peruvian shanty town: implications for control of Campylobacter jejuni-associated diarrhoea. Acta Tropica 100: $1-14$.

45. Reich F, Atanassova V, Haunhorst E, Klein G (2008) The effects of Campylobacter numbers in caeca on the contamination of broiler carcasses with Campylobacter. International Journal of Food Microbiology 127(1-2): 116-120.

46. Rahimi E, Momtaz H, Ameri M, Ghasemian Safaei H, Ali Kasemi M (2010) Prevalence and antimicrobial resistance of Campylobacter species isolated from chicken carcasses during processing in Iran. Poult Science 89 (5): 1015-1020.

47. Padungtod P, Kaneene JB (2005) Campylobacter in food animals and humans in northern Thailand. Journal of Food Protection 68(12): 25192526 .

48. Meldrum RJ, Smith RMM, Wilson IG (2006) Three-year surveillance program examining the prevalence of Campylobacter and Salmonella in whole retail raw chicken. Journal of Food Protection 69(4): 928-931.

49. Fernandez H, Pisón V (1996) Isolation of thermotolerant species of Campylobacter from commercial chicken livers. International journal of Food Microbiology 29(1): 75-80.

50. Kinde H, Genigeorgis CA, Pappaioanou M (1983) Prevalence of campylobacter jejuni in chicken wings. Applied and environmental microbiology 45(3): 1116-1118.

51. Nauta MJ, Jacobs Reitsma WF, Havelaar AH (2007) A risk assessment model for Campylobacter in broiler meat. Risk Analysis 27(4): 845- 861.

52. Cason JA, Hinton AJ, Buhr RJ (2004) Impact of feathers and feather follicles on broiler carcass bacteria. Poultry Science 83(8): 1452-1455.

53. Guevremont E, Nadeau E, Sirois M (2006) Antimicrobial susceptibilities of thermophilic Campylobacter from humans, swine, and chicken broilers. Canadian Journal of Veterinary Research 70(2): 81-86.

54. Praakle Amin K, Roasto M, Korkeala H, Hänninen ML (2007) PFGE genotyping and antimicrobial susceptibility of Campylobacter in retail poultry meat in Estonia. International Journal of Food Microbiology 114(1): 105-112. 
55. Thorsteinsdottir TR, Kristinsson KG, Fridriksdottir V, Gunnarsson E (2008) Antimicrobial Resistance of Campylobacter spp. Isolated from Broiler Flocks. Microbial drug resistance 14(1): 49-53.

56. Dadi L, Daniel A (2008) Prevalence and antimicrobial susceptibility profiles of thermotolerant Campylobacter strains in retail raw meat products in Ethiopia. Ethiopian Journal of Health Development 22(2): 195-200.

57. González Abad MJ, Alonso Sanz M (2013) Incidence and susceptibility of Campylobacter jejuni in pediatric patients: involvement in bacteremia. Revista Española de Quimioterapia 6(2): 92-96.

58. Endtz HP, Ruijs GJ, van Klingeren B, Jansen WH, van derReyden T, et al. (1991) Quinolone resistance in campylobacter isolated from man and poultry following the introduction of fluoroquinolones in veterinary medicine. Journal of Antimicrobial Chemotherapy 27(2): 199-208.

59. Kuschner RA, Trofa AF, Thomas RJ, Hoge CW, Pitarangsi C, et al. (1995) Use of azithromycin for the treatment of campylobacter enteritis in travelers to Thailand, an area where ciprofloxacin resistance is prevalent. Clinical infectious Diseases 21(3): 536-541.

60. Gaudreau C, Gilbert H (1997) Comparison of disc diffusion and agar dilution methods for antibiotic susceptibility testing of Campylobacter jejuni subsp. jejuni and Campylobacter coli. Journal of Antimicrobial Chemotherapy 39(6): 707-712.

61. Reina J (2000) Resistance to fluoroquinolones in salmonella non-typhi and campylobacter spp. Lancet 340: 1035-1036.

62. Kang YS, Cho YS, Yoon, SK, Yu MA, et al. (2006) Prevalence and antimicrobial resistance of Campylobacter jejuni and Campylobacter coli isolated from raw chicken meat and human stools in Korea. Journal of Food Protection 69(12): 2915-2923.

63. Cokal Y, Caner V, Sen A, Cetin C, Karagenc N (2009) Campylobacter spp. and their antimicrobial resistance patterns in poultry: an epidemiological survey study in Turkey. Zoonoses and Public Health 56(3): 105-110.

64. Chen X, Naren GW, Wu CM, Wang Y, Dai L, et al. (2010) Prevalence and antimicrobial resistance of Campylobacter isolates in broilers from China. Veterinary Microbiology 144(1-2): 133-139.

65. Wimalarathna HML, Richardson JF, Lawson AJ, Elson R, Meldrum R, et al. (2013) Widespread acquisition of antimicrobial resistance among Campylobacter isolates from UK retail poultry and evidence for clonal expansion of resistant lineages. BMC Microbiology 13: 160.

66. Komba EVG, Mdegela RH, Msoffe PLM, Matowo DE, Maro MJ (2014) Occurrence, species distribution and antimicrobial resistance of
Thermophilic Campylobacter isolates from farm and laboratory animals in Morogoro, Tanzania. Veterinary World 7(8): 559-565.

67. Samuel SO, Aboderin AO, Akanbi II AA, Adegboro B, Coker AO, et al. (2006) Campylobacter enteritis in Ilorin, Nigeria. East African Medical Journal 83(9): 478-484

68. Kownnhar H, Shankar EM, Rajan R, Vengatesan A, Rao UA (2007) Prevalence of Campylobacter jejuni and enteric bacterial pathogens among hospitalized HIV infected versus non-HIV infected patients with diarrhoea in southern India. Scandinavian Journal of Infectious Diseases 39(10): 862-866

69. Jacobs Reitsma WF, Koenraad PM, Bolder NM, Mulder RW (1994) In vitro susceptibility of Campylobacter and Salmonella isolates from broilers to quinolones, ampicillin, tetracycline, and erythromycin. Veterinary Quarterly 16(4): 206-208.

70. Tambur Z, Miljkovic Selimovic B, Bokonjic D, Kulisic Z (2009) Susceptibility of Campylobacter jejuni and Campylobacter coli isolated from animals and humans to ciprofloxacin. Polish Journal of Veterinary Sciences 12(2): 269-273.

71. Deckert AE, Reid Smith RJ, Tamblyn SE, Morrell L, Seliske P, et al. (2013) Antimicrobial resistance and Antimicrobial use associated with laboratory confirmed cases of Campylobacter infection in two health units in Ontario. Canadian Journal of Infectious Diseases and Medical Microbiology 24(1): e16-21.

72. Carrique Mas JJ, Bryant JE, Cuong NV, Hoang NV, Campbell, J, Hoang NV, et al. (2013) An epidemiological investigation of Campylobacter in pig and poultry farms in the Mekong delta of Vietnam. Epidemiology and Infection 142(7):1425-1436.

73. Wieczorek K, Osek J (2013) Characteristics and antimicrobial resistance of Campylobacter isolated from pig and cattle carcasses in Poland. Polish Journal of Veterinary Sciences 16(3): 501-508.

74. Beatty ME, Ochieng JB, Chege W, Kumar L, Okoth G, et al. (2009) Sporadic paediatric diarrhoeal illness in urban and rural sites in Nyanza Province, Kenya. East African Medical Journal 86(8): 387-398.

75. Nonga HE, Muhairwa AP (2009) Prevalence and antibiotic susceptibility of thermophilic Campylobacter isolates from free range domestic duck (Cairina moschata) in Morogoro municipality, Tanzania. Tropical Animal Health and Production 42(2): 165-172.

76. Ge B, Wang F, Sjölund Karlsson M, McDermott PF (2013) Antimicrobial resistance in campylobacter: susceptibility testing methods and resistance trends. Journal of Microbiological Methods 95(1): 57-67.

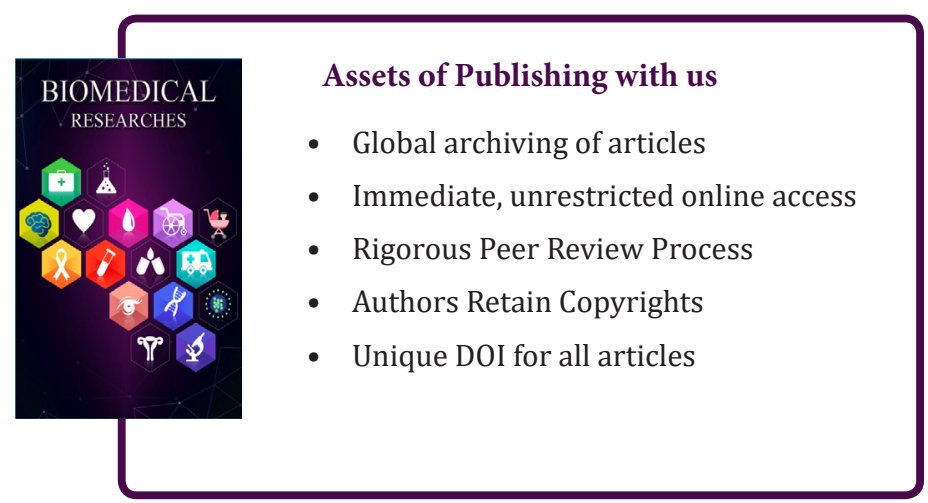

